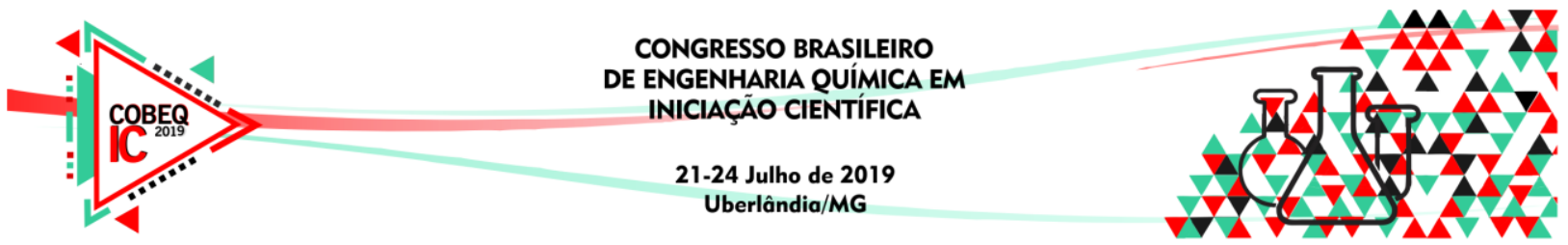

\title{
CARACTERIZAÇÃO DO ÓLEO DE RÍCINO POR MEIO DA TÉCNICA ULTRASSÔNICA
}

\author{
J. G. U. ALVAREZ1 ${ }^{1}$ C. A. M. SILVA ${ }^{1}$, S. V. SARAIVA ${ }^{1}$ e A. M. F. FILETI ${ }^{1}$ \\ ${ }^{1}$ Universidade Estadual de Campinas, Faculdade de Engenharia Química \\ E-mail para contato: j175949@g.unicamp.br
}

\begin{abstract}
RESUMO - Propriedades físico-químicas e acústicas de óleo de rícino comercial foram adequadamente estimadas por meio da técnica ultrassônica, utilizando uma célula construída no Laboratório de Engenharia de Sistemas Químicos da Faculdade de Engenharia Química da Unicamp. As propriedades foram calculadas para várias temperaturas. Foram obtidos desvios da ordem de $0,7 \%$ para o cálculo da massa específica. Evidenciou-se que a célula ultrassônica construída e o processamento do sinal utilizado apresentaram sensibilidade para captar as variações das propriedades com a temperatura e estimar de maneira satisfatória a atenuação acústica, a velocidade do som no meio, e a massa específica do óleo de rícino.
\end{abstract}

\section{INTRODUÇÃO}

O óleo de rícino, derivado da semente da Ricinus communis, é comumente utilizado na hidro acústica por apresentar impedância acústica parecida com a da água e baixo custo (Timme, 1972). Também é utilizado como líquido de referência em medições ultrassônicas por conta da sua alta atenuação acústica, como reportado em Kushibiki et al. (1995) e Moreira et al. (2018). As técnicas ultrassônicas são utilizadas em várias áreas da indústria química para a estimativa de propriedades físico-químicas e acústicas como a massa específica (Adamowski et al. 1993), fração mássica em escoamentos multifásicos (Carlson, 2002) e viscosidade (Cohen-Bacrie, 1999) de maneira rápida e com a possibilidade de atuar de maneira não-invasiva e não-intrusiva.

A fim de calibrar a célula produzida, foram realizadas diferentes medidas ultrassônicas de óleo de rícino varrendo um intervalo de temperatura para a caracterização de propriedades do fluido em função da temperatura, tais como: velocidade do som, massa específica e atenuação acústica.

\section{APARATO EXPERIMENTAL E METODOLOGIA}

\subsection{Célula de medição ultrassônica}

A célula de medição ultrassônica utilizada nos ensaios foi inspirada no trabalho de Bjorndal et al. (2008) e projetada por pesquisadores do Laboratório de Engenharia de Sistemas Químicos (LESQ) da Faculdade de Engenharia Química da Unicamp. O projeto foi feito de maneira a garantir que não exista sobreposição de sinais ecos. Todo 


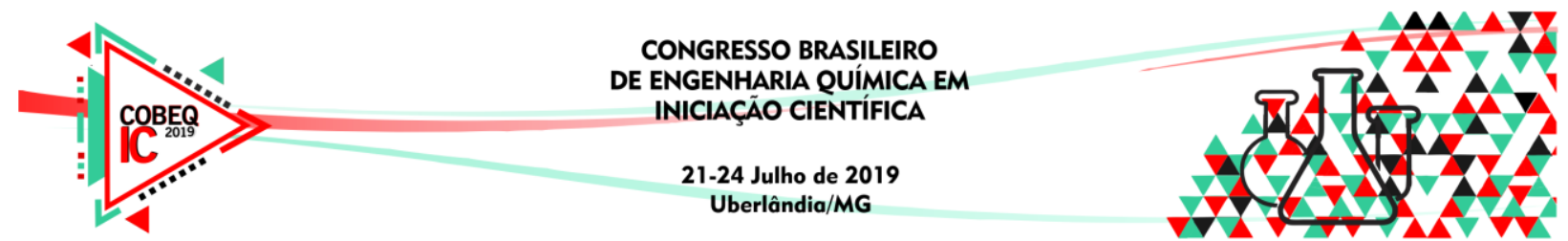

o sistema foi construído em alumínio de qualidade 6082-T6. Sua geometria e o princípio de medição podem ser vistos nas Figuras 1 e 2, respectivamente.

Figura 1 - Geometria da célula utilizada
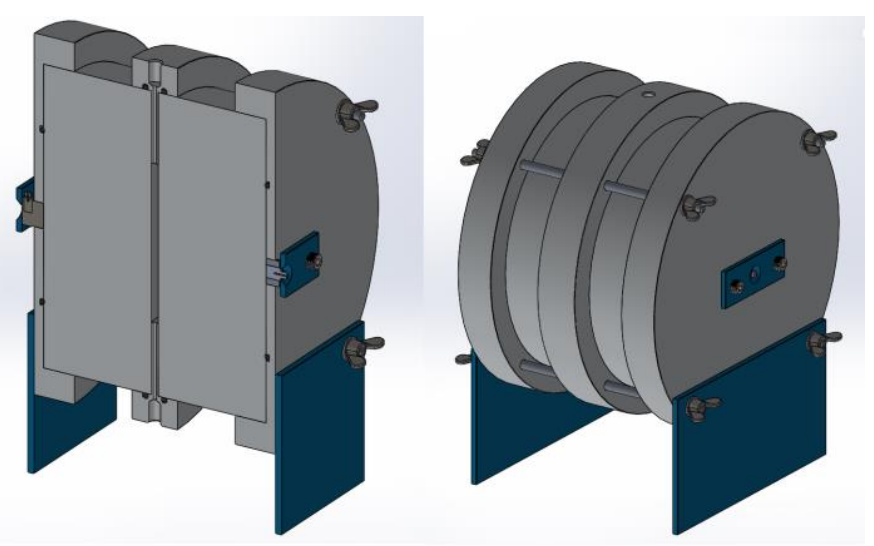

Figura 2 - Princípio de medição e representação do sinal experimental

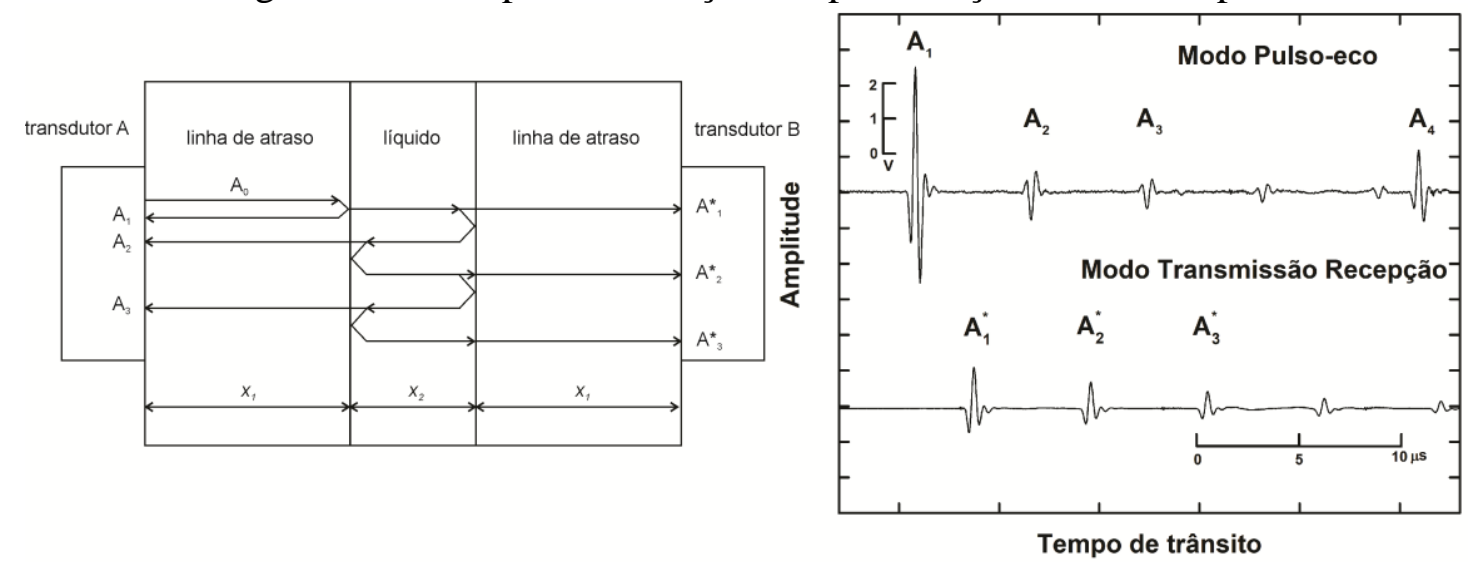

A aquisição de dados ultrassônicos foi realizada por um gerador/receptor de pulsos elétricos Panametrics, modelo 5077PR em conjunto com uma plataforma de medição PXI da National Instruments, composta de um chassi modelo PXIe-1062, um controlador modelo PXIe-8106 e um módulo osciloscópio modelo PXIe-5105 com taxa de amostragem máxima de $60 \mathrm{MHz}$ e resolução de 12 bits. Foram utilizados dois transdutores Panametrics V106 $(2,25 \mathrm{MHz}, 13 \mathrm{~mm}$ de diâmetro) acoplados nas extremidades da linha de atraso. Para a aquisição da temperatura foi utilizado um sensor PT100 com transmissor de temperatura acoplado a um módulo de entrada analógica NI $9203 \mathrm{em}$ um chassi NI cDAQ-9178. Os sinais foram adquiridos por uma rotina em LabView e processados em linguagem Python. A frequência de geração dos pulsos foi configurada em $100 \mathrm{~Hz}$, aquisitando um total de 50 pulsos. Para o controle da temperatura foi utilizado um banho termostático. Para os experimentos foram utilizados água destilada e óleo de rícino da marca Ever Care. 


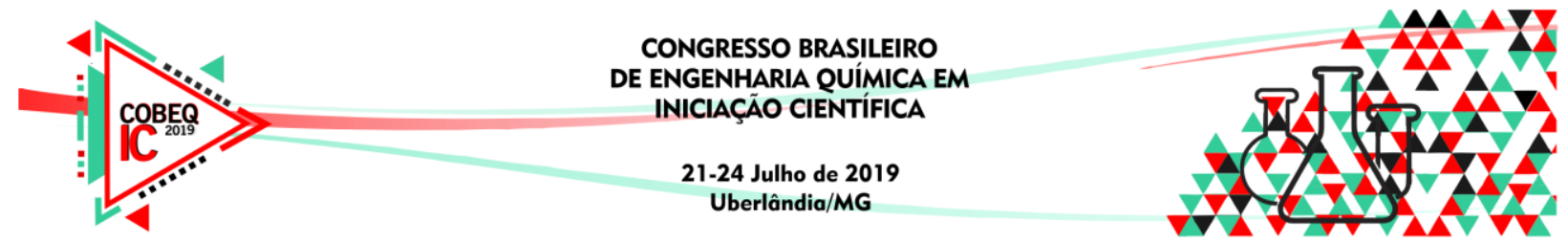

\subsection{Metodologia e equacionamento}

Primeiramente, a câmara de amostra da célula foi limpa com álcool e montada de forma a evitar vazamentos. Após isso, o caminho de propagação da amostra foi calibrado utilizando água destilada como fluido de referência. Para tal, foram utilizados os tempos de trânsito obtidos dos sinais ecos $\mathrm{A}_{1}$ e $\mathrm{A}_{2}$ da água calculados pelo método da correlação cruzada, como reportado em Costa-Júnior et al. (2018), e a correlação da velocidade do som na água em função da temperatura, encontrada em Marczak (1997).

A seguir, a amostra de interesse foi inserida na célula de medição através de uma bomba peristáltica e novas medidas foram obtidas. Com o caminho de propagação previamente calibrado e com o tempo de trânsito foi possível calcular a velocidade do som no meio. As medidas das amplitudes foram calculadas usando a abordagem de integração no domínio da frequência, conforme reportado em Higuti e Adamowski (2002).

O coeficiente de reflexão acústica $\left(R_{12}\right)$ foi então obtido a partir das Equações 1 e 2, onde $f_{1}$ e $f_{2}$ correspondem aos comprimentos de banda dos transdutores. Finalmente, com os parâmetros obtidos, foi possível calcular a massa específica da amostra a partir da Equação 3.

$$
\begin{aligned}
& R_{12}=\sqrt{\frac{x}{x-1}} \\
& x=\frac{\int_{f_{1}}^{f_{2}} A_{1}(f) d f \int_{f_{1}}^{f_{2}} A_{3}(f) d f}{\left(\int_{f_{1}}^{f_{2}} A_{2}(f) d f\right)^{2}} \\
& \rho_{2}=\frac{\rho_{1} c_{1}}{c_{2}} \frac{1+R_{12}}{1-R_{12}}
\end{aligned}
$$

Relacionando ainda as amplitudes $A_{1}$ e $A_{2}$, ou $A_{2}$ e $A_{3}$ ou $A_{1}$ e $A_{3}$, podem ser usadas diferentes equações para a determinação do coeficiente de atenuação acústica da amostra:

$$
\begin{aligned}
& \alpha_{2}=\frac{1}{2 x_{2}} \ln \left(\frac{A_{1}}{A_{2}}\left(R^{2}-1\right)\right) \\
& \alpha_{2}=\frac{1}{2 x_{2}} \ln \left(\frac{A_{2}}{A_{3}} R^{2}\right)
\end{aligned}
$$




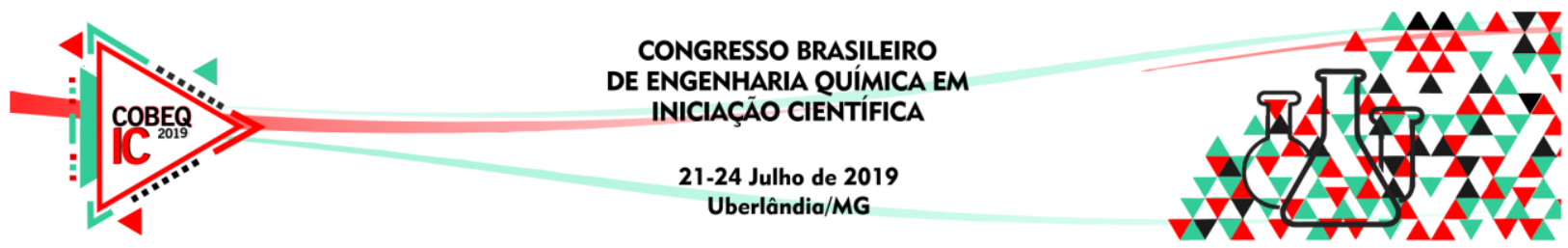

$\alpha_{2}=\frac{1}{2 x_{2}} \ln \left(\frac{A_{1}^{*}}{A_{2}^{*}} R^{2}\right)$

$\alpha_{2}=\frac{1}{2 x_{2}} \ln \left(\frac{A_{2}^{*}}{A_{3}^{*}} R^{2}\right)$

Nestas equações, os valores das amplitudes $\mathrm{A}_{1}, \mathrm{~A}_{2}$ e $\mathrm{A}_{2}$ devem ser acompanhados dos respectivos sinais - positivo ou negativo - de acordo com a fase do eco recebido.

\section{RESULTADOS}

A atenuação do sinal do óleo de rícino pode ser visivelmente verificada pela diferença das magnitudes das amplitudes dos sinais ecos consecutivos, representados na Figura 3a. Com a aplicação a transformada rápida de Fourier (FFT) foi possível verificar essa diferença de magnitude também no domínio da frequência. Isso traduz em uma atenuação elevada, na ordem de $40 \mathrm{~Np} / \mathrm{m}$ a $20^{\circ} \mathrm{C}$. É possível observar pelos resultados obtidos (Figura 3b) que a atenuação diminui com o aumento da temperatura, assim como reportado em Tong e Povey (2002). Os desvios do presente trabalho e dos outros autores podem ser explicados pela diferença da composição do óleo de rícino comercial, que por se tratar de um composto natural, sofre influência dos materiais orgânicos utilizados em sua fabricação.

Figura 3 - (a) Sinais ecos obtidos do transdutor e suas transformadas de Fourier e (b)

Comparação dos resultados para a atenuação em função da temperatura
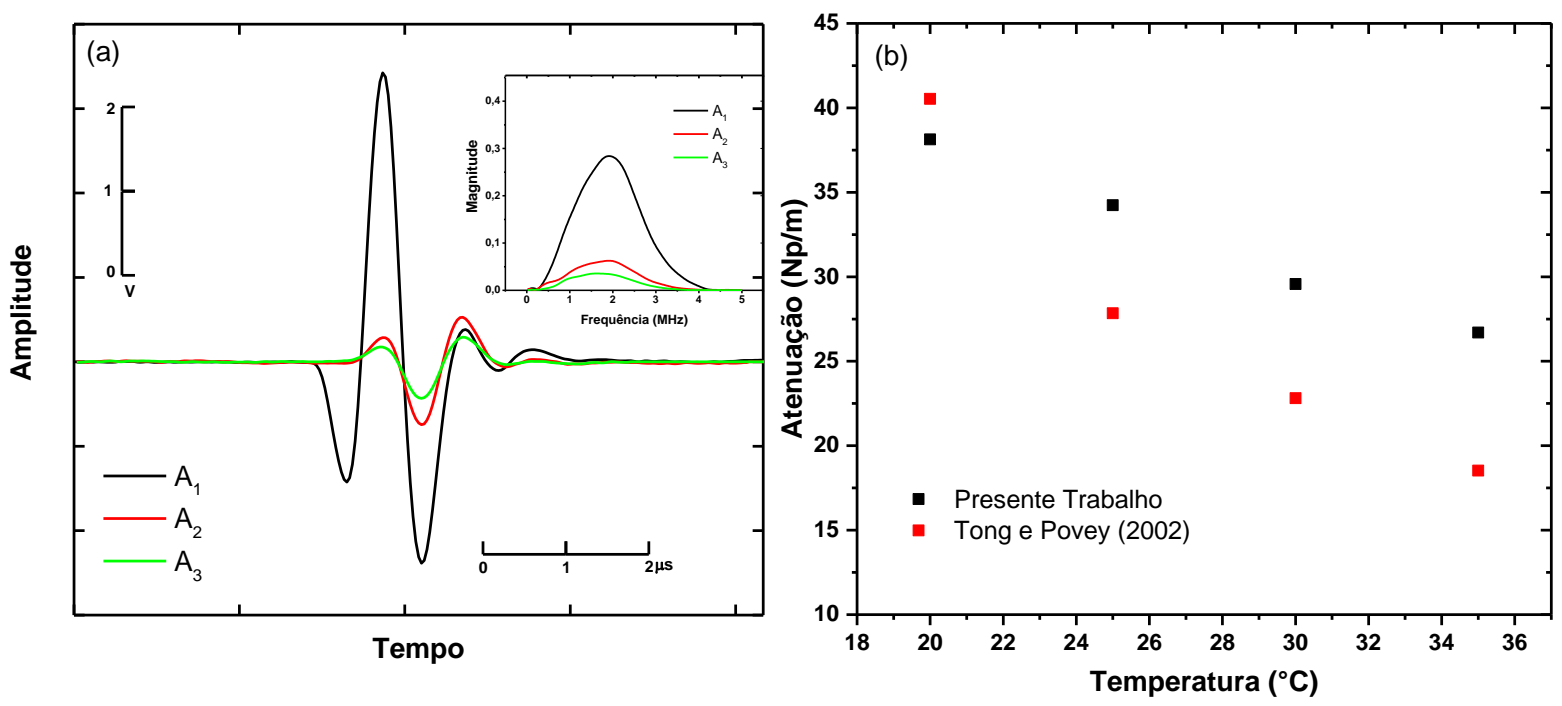

Para as medidas de massa específica, foi obtido além do perfil semelhante um desvio pequeno dos dados presentes na literatura, como pode ser visto na Figura 4. Os desvios máximos foram da ordem de $0,7 \%$ comparando com os dados presentes em Schuele et al. (1957) e Gokdogan et al. (2015).

Para a velocidade do som também foi obtido um perfil concordante com a literatura, porém com desvios na ordem de 5\% em relação aos dados obtidos por Timme (1972). Esses 


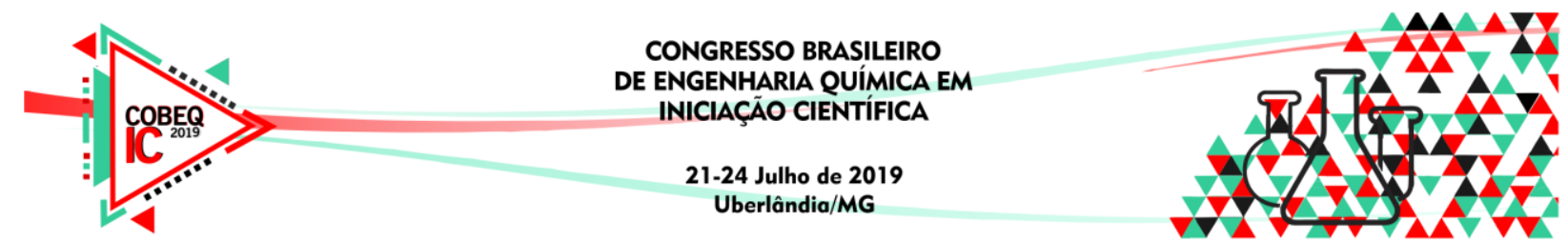

desvios podem ser explicados pela já citada diferença na composição dos óleos, assim como também no método de obtenção dos dados, uma vez que a velocidade do som no óleo de rícino depende da frequência, como observado em Tong e Povey (2002).

Figura 4 - Comparação dos resultados obtidos para a massa específica e para a atenuação, respectivamente.
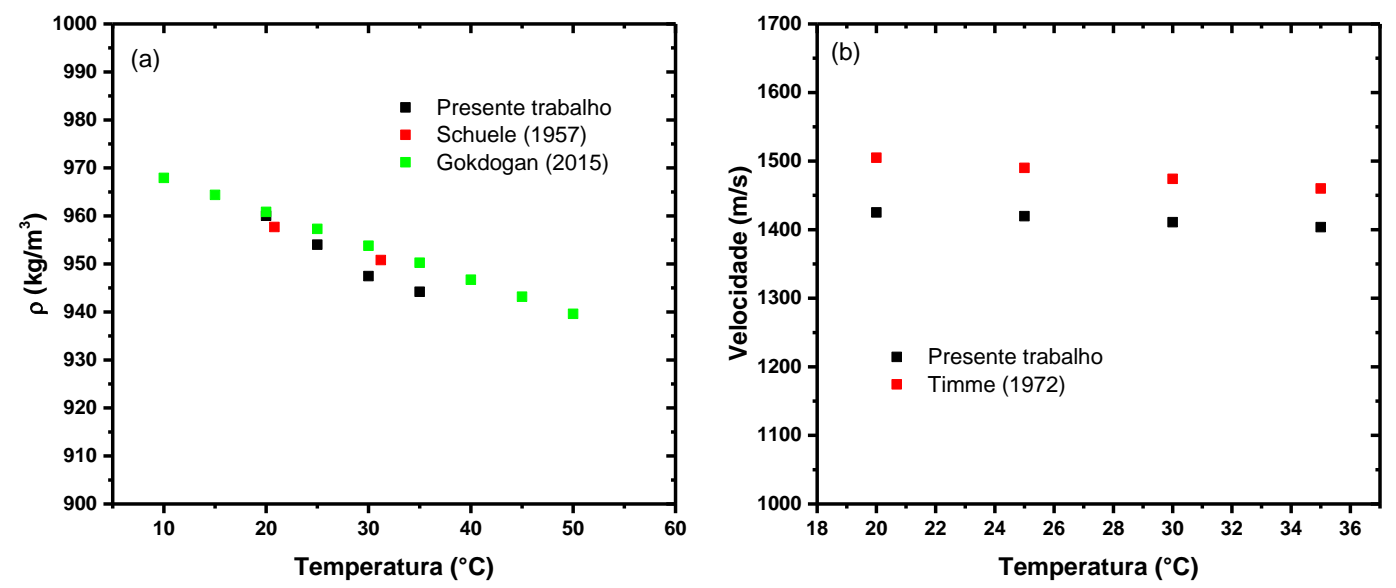

\section{CONCLUSÃO}

A célula ultrassônica construída e o processamento do sinal utilizado apresentaram sensibilidade para captar variações das propriedades com a temperatura, possibilitando estimar as propriedades físicas e acústicas do óleo de rícino. Os resultados obtidos possuem um comportamento semelhante ao apresentado pela literatura. Desvios nas medições podem estar associados às diferentes propriedades físicas dos óleos com processos de produção diferentes (extração, processamento, estocagem, tempo de prateleira, etc) e aos desvios associados aos diferentes tipos de processamentos dos sinais, uma vez que as propriedades calculadas variam também com a frequência.

\section{AGRADECIMENTOS}

Os autores agradecem à CAPES, PETROBRAS e à ANP pela concessão de bolsas de estudos e pelo financiamento do projeto de pesquisa pelo qual foi possível a publicação deste artigo. Agradecemos também ao grupo ALFA do Centro de Estudos de Petróleo da Unicamp pelo auxílio técnico no projeto da célula de medição e pelas discussões realizadas.

\section{REFERENCIAS}

ADAMOWSKI, J.; BUIOCHI, F.; SIMON, C.; SILVA, E.; SIGELMANN, R. Ultrasonic measurement of density of liquids. Acoustical Society of America Journal. 97. 354-361, 1995. 


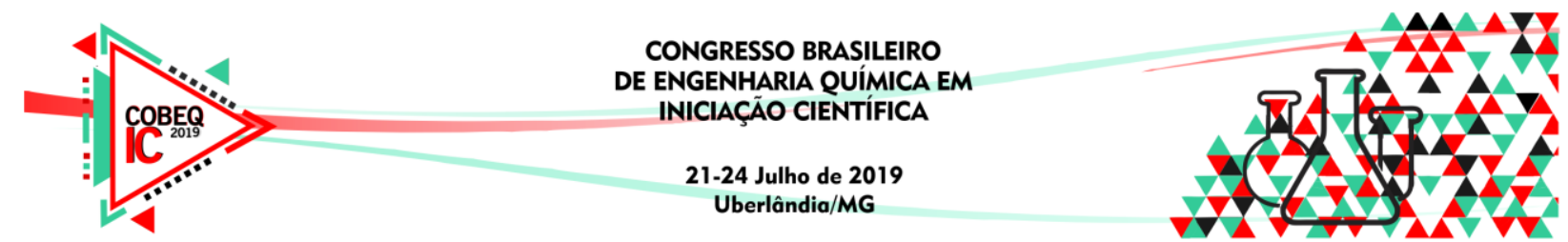

BJORNDAL, E.; FROYSA, K. E.; ENGESETH, S. A.; A novel approach to acoustic liquid density measurements using a buffer rod based measuring cell. IEEE transactions on ultrasonics, ferroelectrics, and frequency control, 2008.

CARLSON, J.; Martinsson, P. E.; A simple scattering model for measuring particle mass fractions in multiphase flows, in Ultrasonics, Vol. 39, Issue 8, 2002, Pages 585-590.

COHEN-BACRIE, C.; Estimation of viscosity from ultrasound measurements of velocity, 1999 IEEE Ultrasonics Symposium. Proceedings. International Symposium (Cat. No.99CH37027), Caesars Tahoe, NV, 1999, pp. 1489-1492 vol.2.

COSTA-JÚNIOR, J. F. S.; CORTELA, G. A.; MAGGI L. E.; ROCHA T. F. D.; PEREIRA W. C. A.; COSTA-FÉLIX R. P. B.; ALVARENGA A. V.; Measuring uncertainty of ultrasonic longitudinal phase velocity estimation using different time-delay estimation methods based on cross-correlation: Computational simulation and experiments. Measurement. J., 122, 45-56, 2018.

GOKDOGAN, O.; ERYLMAZ, T.; YESILYURT, K. M.; Thermophysical properties of castor oil (Ricinus Communis L.) biodiesel and its blends. C.T.F Cienc. Tecnol. Futuro, v. 6; n. 1, p. 95-128, 2015.

HIGUTI, R. T.; ADAMOWSKI, J.C Ultrasonic Densitomer Using a Multiple Reflection Technique, in IEEE Transactions on Ultrasonics, Ferroelectrics, and Frequency Control, vol. 49, no. 9, pp. 1260-1268, 2002.

KUSKIBIKI, J.; AKASHI, N.; SANNOMIYA, T.; CHUBACHI N. and DUNN, F. VHF/UHF range bioultrasonic spectroscopy system and method, in IEEE Transactions on Ultrasonics, Ferroelectrics, and Frequency Control, vol. 42, no. 6, pp. 1028-1039, Nov. 1995.

MARCZAK, W.; Water as a standard in the measurements of speed of sound in liquids. The Journal of the Acoustical Society of America, 102(5), 1997.

MOREIRA, M. T.; HIGUTI, R. T.; SEGURA, L. E.; KITANO C.; ASSUNÇÃO E. and OLIVEIRA S. L.; Versatile Ultrasonic Spectrometer for Liquids With Practical Sample Handling by Using Standard Cuvettes, in IEEE Transactions on Ultrasonics, Ferroelectrics, and Frequency Control, vol. 66, no. 1, pp. 109-118, Jan. 2019.

SCHUELE, D. E.; GUTOWSKI, F. A.; and CAROME E. F.; Interferometric Determination of Ultrassonic Absorption in Castor Oil, in The Journal of the Acoustical Society of America, vol. 29, 1957.

TIMME, R. W.; Speed of Sound in Castor Oil. Journal of The Acoustical Society of America - J ACOUST SOC AMER. 52. 10.1121/1.1913205, 1972.

TONG, J. and Povey, J. W. P.; Pulse echo comparison method with FSUPER to measure velocity dispersion in n-tetradecane in water emulsions. Ultrasonics, Volume 40, Issues $1-8,2002$, pages 37-41. 